\title{
COVID-19 and Working Conditions in Health Care
}

\author{
Töres Theorell \\ Department of International Health, Karolinska Institutet, Stockholm, Sweden
}

There have been many conflicting messages about the new coronavirus SARS-CoV-2. Initially, many of our colleagues were thinking on the basis of the first scant descriptions that this was just a new flu virus - nothing to worry about. However, as more and more experience is accumulating, it becomes obvious that although it is indeed a virus belonging to the flu family, this one has peculiarities which have the potential of straining some of our health care resources to the extreme.

Only a small part of the patients who are infected develop serious breathing problems, but those who do so will need advanced help for a long time. Since there is a limited number of high-pressure respirators, there is a risk that a growing number of patients with the most advanced critical stages of breathing problems will not get any treatment and accordingly will choke to death - despite the fact that the staff have the knowledge about how to save them. All the staff can do in that situation is to observe and give some palliative help. This is of course an extreme ethical provocation for the staff. The problems will be worse for medical doctors and registered nurses who are facing the difficult decisions in concrete situations than for nonmedical staff such as administrators. At the same time, many of their colleagues are on sick leave because they are infected with the coronavirus. Thus, with increasing numbers of patients in the corridor, there will be decreased staff.

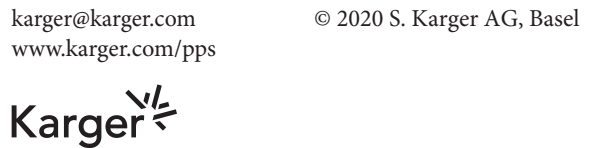

This situation gives rise to the worst possible work environment for health care staff. All of the bad classical psychosocial risk factors in the work environment are magnified - extremely high demands, complete lack of control, lack of institutional support in many workplaces [1], and in addition lack of reward [2]. On top of this, the staff will work with extreme overtime and shift work schedules. This is like a cruel experiment - a randomized trial for maximal worsening of the work environment. There is a large volume of scientific literature supporting that there is increased risk of developing depression, burnout syndrome, and myocardial infarction when employees are exposed to such situations [3-5].

Extreme long-lasting stressors in the work environment give rise to serious physiological problems when time for recuperation and regeneration is insufficient. This has been known for a long time [1].

Zhang et al. [6] have published data from a cross-sectional online survey of medical health care workers who have been working in this terrible situation in China. These participants are compared with a sample of nonmedical health care staff who have been working in the same areas. Not unexpectedly, the medical staff who are more exposed than the others to the ethical dilemmas and the inevitable decisions going against empathy report most anxiety, depression, loss of sleep, and obsessivecompulsive symptoms. We know that when such symp-

Töres Theorell, MD, PhD

Department of International Health, Karolinska Institutet Karlbergsvägen 72B SE-113 35 Stockholm (Sweden) tores.theorell@su.se 
toms last for long periods, they are associated with allostatic overload, a combination of long-lasting energy mobilization with concomitant suppression of regeneration. The latter part of the physiological disturbance leads to vulnerability in all organ systems [7].

So how do we protect our colleagues? The first thing is to monitor the working conditions carefully. Those working in the hospital administration have a heavy responsibility since they have more overview than the others. When resources (material and personnel) are lacking, innovative collaboration with the surrounding society could pay off. Crash courses in intensive care for medical students and use of plastic material intended for other things remade into protective clothes are examples.

Supervisors also have the responsibility to monitor the health of the staff. The study by Zhang et al. [6] shows that simple standardized questionnaires can be used, which should be supplemented with a brief questionnaire assessing the work conditions (demands, decision latitude, and support). A description of a protective program has been published by Cao et al. [8] based upon hands-on recent experience in China. An important part of that program is the repeated use of a short questionnaire supplemented with personal interviews with a representative group of employees. In addition, Wright and Caudill [9] discuss internet-based support based upon cognitive behavioral therapy principles.

The psychosocial work environment literature points at the importance of the following interventions, some of which are specifically mentioned by our Chinese colleagues:

(1) Flexible work schedules that are adapted to the ever-changing situation. In consequence with that, Cao et al. [8] describe work cycle changes towards 4 -h shifts with $4 \mathrm{~h}$ of rest in-between during the most exhausting periods.

(2) Sleep hygiene, which is facilitated by wise shift cycles and good possibilities for undisturbed sleep.

(3) Social support to family members. Worries for family members could add to the caregiver's deterioration in health.

(4) Participation in decision making. This has not been mentioned specifically by our Chinese colleagues, but if employees feel that their own observations and ideas are taken seriously by the supervisors, this contributes to their maintenance of good health.

(5) Facilitation of good coping. This comprises many things. For instance, a professional attitude to selection of patients for advanced care must be taught. There should be clear guidelines to all staff. Everybody must be prepared for ethical conflicts, and difficult decisions must be made in organized ways.

(6) Facilitation of cultural experiences, for instance easy electronic access to films, concerts, and lectures during leisure time. This is emphasized by Cao et al. [8], and there is considerable theoretical support for this [10].

\section{Disclosure Statement}

The author has no conflict of interest to declare.

\section{Funding Sources}

None.

\section{References}

1 Karasek RA, Theorell T. Healthy work: stress, productivity and the reconstruction of working life. New York: Basic Books; 1990.

2 Siegrist J. Chronic psychosocial stress at work and risk of depression: evidence from prospective studies. Eur Arch Psychiatry Clin Neurosci. 2008 Nov;258(Suppl 5):115-9.

3 Theorell T, Hammarström A, Aronsson G, Träskman Bendz L, Grape T, Hogstedt C, et al. A systematic review including meta-analysis of work environment and depressive symptoms. BMC Public Health. 2015 Aug;15(1):738.

4 Theorell T, Jood K, Järvholm LS, Vingård E, Perk J, Östergren PO, et al. A systematic review of studies in the contributions of the work environment to ischaemic heart disease development. Eur J Public Health. 2016 Jun; 26(3):470-7.
5 Aronsson G, Theorell T, Grape T, Hammarström A, Hogstedt C, Marteinsdottir I, et al. A systematic review including meta-analysis of work environment and burnout symptoms. BMC Public Health. 2017 Mar;17(1):264.

6 Zhang W, Wang K, Zhao W, Xue Q, Peng M, Min B, et al. Mental health and psychosocial problems of medical health workers during the COVID-19 epidemic in China. Psychother Psychosom. doi: 10.1159/000507639 [Epub ahead of print].

7 Fava GA, McEwen BS, Guidi J, Gostoli S, Offidani E, Sonino N. Clinical characterization of allostatic overload. Psychoneuroendocrinology. 2019 Oct;108:94-101.
8 Cao J, Wei J, Zhu H, Duan Y, Geng WW, Hong X, et al. A study of basic needs and psychological wellbeing of medical workers in the fever clinic of a tertiary general hospital in Beijing during the COVID-19 outbreak. Psychother Psychosom. doi: 10.1159/000507453 [Epub ahead of print].

9 Wright JH, Caudill R. Remote treatment delivery in response to the COVID-19 pandemic. Psychother Psychosom. doi: 10.1159/ 000507376 [Epub ahead of print].

10 Theorell T. Arts, health and job stress. In: Romanowska J, Nyberg A, Theorell T, editors. Developing leadership and employee health through the arts. London: Springer; 2016. p. 1-53. 